Nina McHale

\title{
Eradicating the rogue assignment Intervention and prevention
}

$\mathbf{T}_{\mathrm{s}}^{\mathrm{t}}$ he student circulation clerk forces a smile over the desk as she replies for the 37 th time that afternoon that the cost of making a photocopy in the library is ten cents, as noted on the sign over the photocopier. The reference librarian politely explains that no, the library uses Library of Congress call numbers, not the Dewey Decimal System, as indicated on the professor's assignment sheet. Next to him at the reference desk, his colleague swallows a grimace as a student presents a sociology bibliography assignment that has been resurrected every fall semester for nearly a decade without revision. Each of these staff members and patrons has fallen prey-not for the first time, not for the last-to a rogue library assignment.

A rogue library assignment is a facultycreated, library-related assignment that, having been developed with the best possible intentions, is in some way out of sync with a library's resources or does not provide students with a thorough introduction to them. Rogue assignments can be recycled from a different time or place, referencing research tools that were discontinued years ago, or worse, were never in the library to begin with. Scavenger hunt-style assignments, while drawing students into the library, teach them little about the process of conducting academic research and are regarded by students as busywork. Rogue "regulars," such as the sociology example, above appear seasonally, unchanged, in spite of the rapid transformations taking place in academic libraries.

Approaching professors about their teaching methods is initially uncomfort- able at best; however, what good is done by students, faculty, librarians, and library staff by allowing a rogue assignment to continue on a rampage of misinformation? If the following approaches for intervening with and preventing rogue assignments are observed, the result will likely be a successful collaboration that improves the student research experience.

\section{Intervention: A proactive approach}

While it is certainly easy to succumb to frustration and simply tell a rogue-bearing student to return to the professor to correct or clarify the assignment, the student then leaves with the impression that library staff are indifferent and uncaring. To take a proactive approach to a rogue assignment, first and foremost, help the student. Second, report the assignment to other library staff that will be affected by it, and third, contact the instructor to correct the problem. This may require simply providing the professor with correct or updated information about library resources or services; however, if the rogue is of a more severe nature, additional steps may be necessary.

Intervention of rogue assignments frequently begins at the reference desk because students with assignments that do not make sense seek help there. A simple explanation may be all that is necessary to thwart the rogue, for example: "Our library uses the Library of Congress Classification scheme, not

Nina McHale is systems librarian at the University of Colorado-Denver, e-mail: nina.mchale@cudenver.edu (c) 2008 Nina McHale 
the Dewey Decimal system." If the assignment refers to an out-of-date or discontinued resource, offering an alternative that allows the student to gather the information needed to complete the assignment may suffice.

For example: "Well, we no longer receive hard copies of Classical and Medieval Literature Criticism, but much of the content is provided in the Literature Resource Center database." Granted, these are steps that anyone trained in the reference interview knows to take; however, it can be all too easy to take offense at a faculty member's perceived ignorance. If the student is still anxious for not following the assignment to the letter, it is reassuring to explain that a member or the library staff will follow up with the professor. A photocopy of the assignment will document the problem so that it may be dealt with consistently among library staff.

A more serious situation may present itself, particularly in smaller academic libraries, when an entire class descends at once to complete a scavenger hunt exercise. This may create lines at public service desks and computer terminals, as well as noise levels that are distracting to other patrons. If an instruction space is available, reference and instruction staff can conduct an instruction session on the fly to lessen the distraction and provide the students with the rogue assignment with the information that they need in addition to a personalized welcome.

The next step in the intervention process is to report the rogues to colleagues who are likely to be affected by the assignment. Keeping a $\log$ in a notebook, department blog, or other generally accessible place helps track progress with the assignments, both in terms of handling how to help students and making contact with the professor. If an assignment has become a perennial problem, such a log can be a means of gathering staff feedback on alternatives that could be presented to the assignment's creator.

Depending upon the level of severity of the rogue assignment, intervening with teaching faculty could range from a fiveminute phone call to months of collaboration. Regardless, when library staff members make initial contact, they should express sheer delight that the professor is including the library in the coursework. If the assignment is a low-level rogue and needs only some clarification or correction, as in the Dewey Decimal/Library of Congress example above, offer those corrections, and let the professor know that the reference staff will handle encounters consistently until a correction is made. If there is a larger issue with the assignment, requesting a meeting to discuss how to collaborate to better meet student needs may be appropriate.

To prepare for such a meeting, refer first to the photocopy of the rogue assignment and tease out the professor's research objectives, relative to the discipline taught. The situation may seem hopeless, but even the lowly scavenger hunt sends a message to students that the library is important. However, students will receive this message more clearly if a library assignment is linked to a research assignment that they will complete for the course. Reviewing the official course description as posted in the school's course catalog can provide additional hints in connecting a research assignment to the objectives of the course.

Finally, have an alternative assignment on hand for the meeting. If there is an assignment that has been created for a similar class that could be used as-is or would be adaptable, bring it. If nothing appropriate currently exists, it takes only a few minutes to draft a sample assignment or, at the very least, an outline of a sample assignment. At the very least, bring a list of resources or a related subject guide to generate ideas. Ask the professor what the course assignments and requirements are, and chances that an appropriate place for a library-related assignment-including an information literacy session taught by library staff-will be quickly identifiable. Faculty will almost always be delighted that library staff are willing to take on teaching a session of their class. 
Sticky situations may arise. Busy professors may not return e-mails or phone calls. Promises to revise an aging assignment may go unfulfilled. If an instructor has had ample opportunity to respond, consider taking the issue to the next level. Broach the subject in a similar fashion with the department chair: request a meeting, delight that instructors are incorporating the library and its resources into the curriculum, and provide concrete suggestions for enhancing the experience for faculty, students, and library staff.

\section{Prevention}

Now that the existing rogues are corralled, what can be done to prevent more from cropping up in future semesters? The mere existence of a formal information literacy program is one vanguard, but may not be enough in and of itself. Market librarians as assignment consultants and co-teachers, identify "offending" groups of instructors, and provide sample assignments for instructors to use.

First, advertise the library's teaching staff as assignment consultants as often as possible. Participate regularly in faculty development exercises or other perennial campuswide events. Coordinate training sessions on creating effective research assignments that tie directly into existing resources. Make library staff fixtures at departmental meetings. As many students are shy about "bothering" librarians for research help at the reference desk, faculty may feel the same about approaching library staff when it comes to teaching research. Some may not even be aware that information literacy goes beyond offering a general orientation session or tour. Others may assume, "They did that in English composition, right?"

\section{Online extra}

Visit the May 2008 issue of CERL News online at www.acrl.org/c\&rlnews for a podcast interview with article author Nina McHale and to comment on dealing with vague assignments.
Second, identify and target particular groups of offenders. Colleges and universities are more frequently drawing teaching talent from large pools of adjunct faculty. Adjunct professors often teach at more than one institution, and they may use common research assignments for all of their students to save time. They are likely not familiar with the local information literacy program, or they may not feel eligible for the same level of support that is offered to permanent faculty.

Reach out to adjuncts: What orientation activities are offered to them each semester? When and where do they meet? How do they communicate? Make yourself or a member of your teaching staff a permanent part of these activities. Create targeted literature such as a flier or a special Web page that summarizes library resources and services for adjuncts. Create services for adjuncts, if there are none. For example, at the suggestion of one of Howard Community College's department chairs, Clark Library reference staff developed an adjunct faculty library orientation program. Adjuncts were to meet with a librarian or attend a librarian-lead faculty development session at least once a year in order to renew their teaching contracts.

Another common group of offenders are instructors who teach introductory courses, such as English composition. These are the kinds of courses typically assigned to adjunct faculty, but permanent faculty may offend at this level, as well. These courses often have a coordinator to ensure that benchmarks are established and met across all sections taught. Chances are, this person would be delighted to collaborate on a common assignment that ties into these requirements. You will be saving the time of all who teach the course, and your efforts will be appreciated.

If there is no course coordinator, approach the chair of the department with a concrete example of the type of exercise you have in mind. Again, check course catalog descriptions and review the rogues 
to determine the assignment and course objectives.

Third, create a sampling of assignments that are easily updateable and either generic or quickly adaptable to cover the most common types of assignments. Post these on the library's Web site in an easily printable or downloadable format, such as a PDF. Include with each sample assignment a description of how the assignments tie into an information literacy session taught by your staff. These may grow legs; an assignment created for Howard Community College in Columbia, Maryland, once drifted 28 miles south to the Lauinger Library reference desk at Georgetown University-a reminder that, as previously mentioned, adjunct faculty often teach at more than one institution.

Finally, maintain a "Rogue Assignments" file in your desk. Keep a copy of the original with your solution attached. These are prime examples of handling challenging situations tactfully and professionally at review, résumé, or interview time. Outside of your desk, establish a departmental collection of assignments to which all teaching librarians and staff can refer and contribute.

The benefits of proactively wrangling rogue assignments are obvious and threefold: improved student research experiences; increased opportunity for library-faculty collaboration; and, ultimately, far fewer of those nasty rogue assignments running rampant through the stacks. Intervention-developing reference policies for intervening with students and contacting professors when rogues appear-and prevention-marketing teaching services, targeting "offending" groups, and leading by example with sample assignments-are your weapons of choice for eradicating the rogue assignment.

\section{Note}

1. Examples can be found at carbon. cudenver.edu/ nmchale/publications/. Included here are an annotated bibliography assignment and a research journal assignment. $\pi$

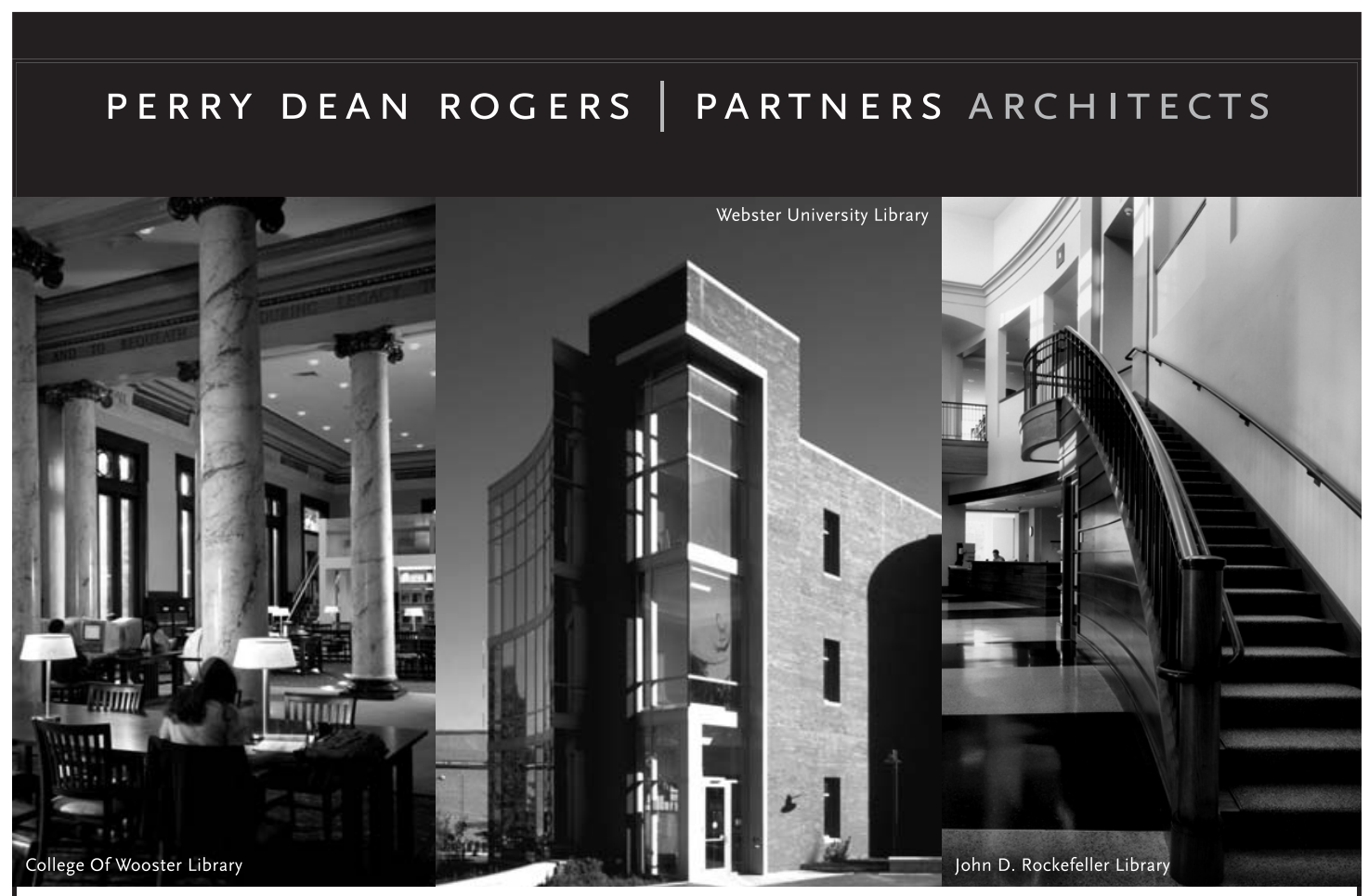

Designers for Libraries \& Academic Institutions 